\title{
Responsibilism within Reason
}

\author{
Kurt Sylvan
}

\section{IO.I Introduction}

According to ambitious responsibilism (AR), ${ }^{\mathrm{I}}$ the virtues that are constitutive of epistemic responsibility should play a central and fundamental role in traditional projects like the analysis of justification and knowledge. While AR enjoyed a shining moment in the mid-I990s, it has fallen on hard times. Part of the reason is that many epistemologists - including fellow responsibilists - think it paints an unreasonably demanding picture of knowledge and justification. While AR's defenders have responses to this worry, they tend either to collapse AR into a much less ambitious view, or to threaten virtue's explanatory force in AR's analyses.

I agree that such objections undermine AR's existing versions. But I think it would be premature to draw the curtains on the view. My goal is to show that the stock objections only threaten the periphery of certain versions of $A R$, and to develop a novel version that avoids them. With this goal in mind, here is the plan. I will begin in Section 10.2 by clarifying the core commitments of AR and explain how influential responsibilists have added to these commitments in optional ways. In Section I0.3, I will rehearse the standard objections to AR, explaining why they only target optional accretions. I'll then turn in Section I 0.4 to develop a version I call Kantian Responsibilism (KR). KR is a two-level view, consisting of (i) a high-level analysis of epistemic normativity in responsibilist terms, and (ii) a first-order account of the conditions under which these terms apply. According to KR's first tier, epistemically virtuous thought is thought that

\footnotetext{
I This is my shorter and less loaded name for what Baehr (20I I) calls strong conservative responsibilism. Note that Baehr usefully distinguished weak and strong as well as autonomous and conservative responsibilism. Weak versions hold that responsibilist virtue properties play an important but auxiliary role in epistemology, while strong versions hold that they play a central role; autonomous versions hold that traditional projects in epistemology ought to be replaced by independent inquiry into intellectual virtue, while conservative versions maintain that virtue epistemology can contribute to traditional projects.
} 
manifests respect for truth; because I hold that manifesting certain reasonssensitive dispositions is necessary and sufficient for respecting truth, KR's second tier takes epistemic virtues to coincide substantively with reasonssensitive dispositions. After unpacking KR in Section I0.4, I show in Section I0.5 how it answers the objections to AR. I close in Section I 0.6 by making some broader points about KR's virtues, especially when compared with reliabilist virtue epistemology.

\section{I0.2 AR: Core and Periphery}

Let's begin by recalling how responsibilism developed in response to the early reliabilist virtue epistemology of Ernest Sosa.

When first formulated by Sosa (I980), virtue epistemology (VE) was offered as a contribution to traditional projects concerning the nature and structure of knowledge and justification. In this formulation, VE was not sharply distinguished from the simple reliabilism of Goldman (I979); indeed, the title of Sosa's (I980: 23) key section was 'Reliabilism: an ethics of moral virtues and an epistemology of intellectual virtues.' This feature prompted a demand for a stronger break with tradition, with Code (I 984: 47) suggesting in responsibilism's first articulation that we should 'offer a different approach to epistemology, based upon an entirely different set of expectations from those that have long constituted the fundamental motivations of foundationalism and coherentism,' and hold that traditional epistemology's 'methodologies, but also ... the presuppositions and expectations that underlie them, are misguided'. Kvanvig (I992) echoed Code's thought more seditiously, recommending that we ditch traditional epistemology for the independent study of epistemic virtue.

Early responsibilism's radicalism was tempered in mid-I990s by Zagzebski's landmark Virtues of the Mind, which offered accounts of knowledge and justified belief meant to rival Sosa (I99I). Zagzebski (I996) remains AR's high watermark. Unfortunately, however, this watermark has been maintained partly because many virtue epistemologists have rejected Zagzebski's project. Some have returned to the autonomous VE of Code and Kvanvig. ${ }^{2}$ Others have sought compromises. Baehr (20I I) advocates a 'weak conservative' responsibilism that agrees on the importance of traditional epistemological projects yet holds that responsibilist virtue has a merely auxiliary role in them. Some reliabilist virtue epistemologists, on the other hand, now deny that there is a real tension between their projects and

2 See Roberts and Wood 2007. 
responsibilists', recommending a merger. For example, Greco (2010) invokes both responsibility and reliability in his account of justification, while Sosa (2015) suggests that responsibilist themes follow from reliabilist VE properly understood.

While the hope of defending an undiluted responsibilism as ambitious as Zagzebski's has disappeared, I think this pessimism rests on mistaking peripheral features of certain versions of AR for core features. None of the objections to Zagzebski (I996) undermine AR when core and periphery are distinguished, as we'll see.

\section{I0.2.I The Core}

As I understand it, AR's fundamental claim is simple:

$\left(A R_{C}\right)$ Responsibilist virtue properties should play a central and fundamental role in the analysis of epistemically normative properties.

Three parts of this claim require unpacking, however, raising three questions for AR:

QI: What are 'responsibilist virtue properties'?

Q2: What does it take to play a 'central and fundamental role'?

Q3: What counts as an epistemically normative property?

I think many objections to $A R_{C}$ rest on false assumptions about how we should answer QI-3.

On Q3. To understand what $\mathrm{AR}_{\mathrm{C}}$ says, we need minimal answers to QI-3 that existing defenders of $A R_{C}$ and I would both accept. Proceeding backwards from Q3, we can start with the truism that epistemically normative properties are a special case of normative properties, where 'normative' is understood broadly to include the normativity associated with standards of correctness that fall short of all-things-considered significance, like norms of prescriptive grammar and etiquette. ${ }^{3}$ Normative properties across domains then come in various flavors. There are evaluative properties, including thin ones like goodness and badness, and thick ones like courageousness, shrewdness, and grubbiness. There are also deontic properties, most obviously including permissibility and obligation,

\footnotetext{
3 'Normative' is sometimes used more narrowly for standards we ought objectively to care about; see, e.g., Kolodny 2005 and Broome 20I3. It is unclear whether epistemology is normative in this sense. Early responsibilists like Code (1984) took it to be a virtue of their view that it made epistemology normative in this sense, but I remain unsure.
} 
but also justification in my book. ${ }^{4}$ Finally, there are what Zimmerman (2002) calls hypological properties - blameworthiness, excusability, and praiseworthiness. Normative properties and relations are either paradigmatic members of one of these categories, or ones analyzable in terms of these. Epistemically normative properties and relations are ones hose normativity is tied to the constitutive aims or norms of believing. ${ }^{5}$

Note that when epistemically normative properties and relations are understood in this way, it is not so clear that knowledge is normative. Knowledge might well be the norm of belief, in the sense of being what we need in order to believe permissibly. But something can be the norm of something else without being normatively constituted. Pleasure might be the norm of desire, for example, but it is just a psychological state. Similarly, it is compatible with treating knowledge as the norm of belief to hold that knowledge is just a generic factive mental state that has as species states like seeing that $\mathrm{p}$ and hearing that $\mathrm{p}$. Since this view is not obviously false, we shouldn't include knowledge among the paradigmatically items.

If knowledge were analyzable in terms of justification, it would be normative in our sense, by having as a constituent a paradigmatically normative property. But this claim is neither obvious nor an essential part of the traditional epistemology to which AR contributes. The tradition includes a strain of non-normativism about knowledge: Goldman (1967) and Dretske (I98I) were surely key moments in traditional epistemology, even if they involved broke with a yet older orthodoxy.

On Q2. Let's consider now how one might neutrally answer Q2. By talking about a 'central and fundamental role,' defenders of AR have in mind (a) that responsibilist virtue properties do the bulk of the analytical work, with other properties playing a merely enabling role, and (b) that these properties cannot be replaced without loss of explanatory power by other properties.

\footnotetext{
${ }^{4}$ Alston (1989) recommended viewing justification as a merely evaluative property. But this insistence involved two mistakes. First, Alston assumed that voluntary control is a precondition for deontic assessment, which has been rightly questioned by doxastic compatibilists like Hieronymi (2008) and McHugh (20I4). Second, even if Alston were right that voluntary control is a precondition for deontic assessment, we shouldn't deny that justification is a deontic property: we should rather stop talking about justification and replace it with talk about epistemic goodness.

5 Teleologists would prefer the ideology of aims and their opponents would prefer the ideology of norms, broadly understood to include constitutive standards and not just deontological injunctions. This distinction between teleological and non-teleological theories crosscuts the distinction between $\mathrm{VE}$ and non-virtue-theoretic epistemologies. Some virtue epistemologists (e.g. Sosa and Greco) are teleologists. Responsibilists inspired by Aristotle may also count as teleologists. But responsibilists can reject teleology.
} 
To see what is meant by (a), we can contrast versions of AR with theories that partly invoke responsibilist virtue, like Greco's (2010). According to Greco (2010: 42), a belief is fully epistemically virtuous iff it is both a manifestation of an objectively reliable disposition and epistemically responsible, where epistemic responsibility consists in manifesting the dispositions constitutive of being motivated to believe the truth. This account is not purely reliabilist. But it is not a version of AR, since reliability is equally foregrounded. Reliability is also fundamental on Greco's theory - it isn't treated as significant merely because it follows from a more basic responsibilist requirement. This point matters, since it is often forgotten that Zagzebski (I996) agreed that full epistemic virtue entails reliability, but maintained that reliability's significance derives from a responsibilist virtue requirement.

Hence, while Zagzebski and Greco agree that manifestations of reliabilist and responsibilist virtues are equally necessary for some central epistemic statuses, Zagzebski doesn't treat the former as fundamentally explanatory. So only Zagzebski qualifies as a defender of AR. Greco (2010) is, however, closer to AR than Sosa (2015). Sosa's latest view is the mirror image of Zagzebski's, seeking to derive responsibilist themes from a unified competence-theoretic framework.

On $Q_{I}$. Whether Sosa's reduction of responsibilist virtue to competencetheoretic virtue works partly depends on what counts as a responsibilist virtue property. Here some room for variation among responsibilisms has been strangely overlooked.

According to the standard answer to $Q_{1}$, responsibilist virtue properties are character traits of the sort ascribed to persons when we deem them (e.g.) open-minded thinkers. I have elsewhere argued that responsibilists ought to ditch the emphasis on character traits in general and rich traits like open-mindedness and intellectual courage in particular, ${ }^{6}$ and I build on this point below. But there is a simpler objection to this answer to QI: it omits any mention of epistemic responsibility!

Perhaps previous responsibilists implicitly assumed that the best way to analyze responsibility will be via the manifestation of character traits, and jumped to articulating AR characterologically to forestall questions about epistemic responsibility. But whatever the reason, I don't think the characterological gloss belongs in a neutral characterization of responsibilism. It reflects a substantive and, I think, false theory about epistemic responsibility.

\footnotetext{
${ }^{6}$ See Sylvan 2017.
} 
A more natural and neutral characterization would appeal directly to epistemic responsibility, leaving various substantive theories open: responsibilist virtue properties will be virtue properties that can be instantiated only by subjects with the capacity for epistemic responsibility. There is then an independent question about what counts as a virtue property. Here again previous responsibilists jumped the gun in assuming that virtue properties are fundamentally instantiated by persons rather than acts and attitudes. In ethics, there is an opposing tradition represented by Thomson (1997), Hurka (2006), and Harman (200I) according to which virtue terms apply most fundamentally to acts and attitudes, where applications to persons get analyzed in these more fundamental terms. While Hurka is not a virtue ethicist, Harman and Thomson uphold a novel version of virtue ethics. VE can make the same move, as I noted in Sylvan (2017).

The move gains plausibility from two points. The first is Hurka's (2006) point that a person who isn't virtuous can sometimes perform virtuous acts and merit high praise for them. The second point is that analyzing the act's virtuousness as its being the sort of act a virtuous person would perform is unhelpfully indirect as well as extensionally inadequate. ${ }^{7}$ Even if the virtuous person would have performed this sort of act, this particular act might be performed for vicious reasons. Of course, one might add that the act be done for the sorts of motives the virtuous person would have. But the particular motives could have been acquired only in virtue of past viciousness. Instead of adopting these unhelpfully indirect analyses, I suggested in Sylvan (2017) that it is at least as plausible to appeal directly to virtuous acts and attitudes, and characterize virtuous people as people who tend to do virtuous acts or form virtuous attitudes. I won't repeat my arguments for this view. Here what matters is that virtue properties cannot be neutrally characterized as traits or global dispositions, since this characterization prejudges the substantive question of whether person-attaching virtue properties are fundamental.

How can we give a more neutral characterization? One straightforward way involves linguistic ascent. There is a recognizable class of virtue terms, like 'conscientious,' 'open-minded,' and 'courageous.' These terms apply not just to persons, but also acts, attitudes, and motives independently of what we think about the person generally. With these points in mind, we can give the following neutral characterization of responsibilist virtue properties:

7 Cf. Sylvan 20I7: I39. 
Responsibilist Virtue Properties (RVP): A responsibilist virtue property is a property ascribed by a virtue term (e.g. 'conscientious') whose felicitous use presupposes that the relevant subject has the capacity for epistemic responsibility.

Core $A R$ is then the view that upholds $A R_{C}$, with responsibilist virtue properties understood according to RVP, and the notions of epistemic normativity and a 'central and fundamental role' understood in the foregoing ways.

\subsubsection{The Periphery}

This neutral characterization makes it easy to see how existing versions of AR add peripheral assumptions about (i) epistemic responsibility, (ii) the scope and priority of virtue properties, and (iii) which specific responsibilist virtue properties should figure in the analysis of epistemic normativity. We should realize that there might be better versions of AR that drop these assumptions.

While Zagzebski is not AR's only defender, I'll use her version to illustrate some accretions wrongly regarded as representative of AR. Similar points apply to other existing versions of AR, but I focus on Zagzebski because her version is best known, and its reception strongly affected AR's generally.

Zagzebski makes five key peripheral choices. First, she understands virtues as stable character traits. Second, she understands virtuous epistemic motivation as the desire for knowledge or, in other work, the love of truth. Third, she assumes that there is a tight connection between responsibility and character traits. Fourth, she holds that epistemic virtue is a kind of moral virtue. Fifth, Zagzebski's responsibilist analyses of knowledge and justified belief are indirect in a way that threatens virtue's explanatory force: for example, Zagzebski doesn't require that justified beliefs actually manifest virtues, but just that justified believers believe the sorts of things and have the sorts of motivations that virtuous people would.

Some of these choices can be observed in Zagzebski's (I996: I37) account of virtue:

A virtue, then, can be defined as a deep and enduring acquired excellence of a person, involving a characteristic motivation to produce a certain desired end and reliable success in bringing about that end. 
This account of virtue illustrates Zagzebski's emphasis on character traits. ${ }^{8}$ It also illustrates her emphasis on a certain sort of motivation. Her characterization is already questionable by invoking a motivation to produce a desired end, which seemingly excludes non-consequentialist and nonHumean virtues such as respect from counting. As Scanlon (I998: I04-105) and Parfit (201 I: 237-239) observe, respect for life needn't require desiring or seeking to preserve life in every case (consider assisted suicide and voluntary euthanasia). Perhaps it is necessarily true that there is some end or other that one ought to desire to produce whenever one manifests respect for a value $\mathrm{V}$. But this fact is not what makes respect for $\mathrm{V}$ a virtue: if one ought to desire that end, it is because one ought to respect $\mathrm{V}$, not vice versa.

Zagzebski's characterization of the motivational requirement on epistemic virtue is yet more problematic. In Zagzebski (I996: I68-I76), the relevant motivation is the desire to acquire knowledge, though Zagzebski (2003) later emphasized the desire to acquire truth. As we'll see in Section I0.3, these ways of understanding the motivational requirement on epistemic virtue lead to serious objections: when the motivational requirement is understood in these ways, it is unclear how knowledge and justified belief can be helpfully analyzed in terms of epistemic virtue.

The fourth and fifth features of Zagzebski's view emerge later in the book. Realizing that it is too demanding to expect every case of justification to involve a manifestation of virtue in her sense, Zagzebski (I 996: 24I, my emphasis) adopts a counterfactual analysis:

A justified belief is what a person who is motivated by intellectual virtue, and who has the understanding of his cognitive situation a virtuous person would have, might believe in like circumstances.

As we will see in Section I0.3, this indirectness creates an explanatory problem: it is hard to see how we can helpfully explain the actual justifiedness of your belief in terms of the would-be virtuousness of some counterfactual person who may have reasoned differently. Zagzebski's (I996: 27I) account of knowledge may seem more direct:

Knowledge is a state of belief arising out of acts of intellectual virtue.

\footnotetext{
${ }^{8}$ Her stress on character traits seems a consequence of a more fundamental view about the relationship between character and responsibility, which is dubious for reasons familiar from the literature against 'true self accounts of moral responsibility (see, e.g., Wolf 1994). Zagzebski I996: I 25 tells us that 'the kind of responsibility we think of as distinctively moral and the praise and blame that accompanies it are associated with traits that are acquired gradually in the course of forming habits.'
} 
But in reading this claim, we must remember her account of acts of intellectual virtue:

An act of intellectual virtue $\mathrm{A}$ is an act that arises from the motivational component of $A$, is something a person with virtue $A$ would (probably) do in the circumstances, is successful in achieving the end of the A motivation, and is such that the agent acquires a true belief ... through these features of the act. (1996: 270)

The resulting account of knowledge faces an explanatory problem like the one that faces the account of justification owing to the indirect, counterfactual nature of the second clause.

A final controversial feature of Zagzebski's view is its claim that intellectual virtue is a kind of moral virtue. ${ }^{9}$ When combined with her analyses of justification and knowledge, this claim suggests that a belief cannot be justified or knowledgeable if it is not a belief a morally virtuous person would have. It is not clear why we should agree. One might have thought there can be epistemically justified but false moral beliefs. It will be hard to agree that the morally virtuous person would have them. Merely requiring that they might have them doesn't give us a sufficiently precise yardstick for sorting justified and unjustified beliefs. (Of course, one might deny that there can be justified false moral beliefs, or that fully morally virtuous people could form epistemically unjustified beliefs. But it would be nice not to make AR rest on such claims.)

\section{I0.3 The Standard Objections to AR are Objections to the Periphery}

We can now see why the standard objections to AR are only objections to peripheral features, such as the foregoing five in Zagzebski's view.

Let's back up and recall the objections. Some of the most persuasive cases against AR have appeared in the last decade - especially in Alfano (20 I 2), Baehr (20 I I), Dougherty (20 I I), Olin and Doris (20 I 2) and Sosa (2015). But the central dilemma was already clear in early responses to Zagzebski (1996) - especially Alston (2000), Greco (2000), and Kornblith (2000). Since these papers were published in 2000, I'll call this dilemma the 'Y2K Dilemma.'

Alston (2000) pressed the first horn. He found it unclear how Zagzebski's account accommodates ordinary cases of knowledge and justified

9 See Zagzebski 1996: 256-258. 
belief. Suppose you inadvertently come to know there's a red book on the table by catching a glimpse of it and automatically forming the belief. One might doubt that you manifest any motivation to acquire knowledge or truth. Extending Alston's point, one might find it implausible that any of the distinctive components of Zagzebski's analysis are necessarily satisfied by perceptual knowledge and justified belief.

There are ways out for Zagzebski, but they invite the dilemma's second horn. Consider justified belief first. Zagzebski might insist that even if you aren't virtuously motivated or exhibit virtuous character in believing, your belief is the sort a person with such character and motivation would have. And all Zagzebski requires for justification is that this is true. But while this point shows that the case is not a direct counterexample, it raises a question about the explanatory significance of Zagzebskian virtue, asGreco (2000) ) and Kornblith (2000) stressed. It is unclear how we can explain your beliefs justification by appealing to some counterfactual person's virtues. Zagzebski's account of knowledge doesn't so clearly invite this worry, since it imposes an actual motivational requirement. ${ }^{\text {IO }}$ But even if this requirement is met by ordinary virtuous subjects, one might find it explanatorily superfluous.

There are more and less compelling versions of this objection. I don't agree with Greco (2000) that some purely reliabilist feature does the explanatory work instead. When it comes to the kind of knowledge that entails justification, there is an important difference between clairvoyance and blindsight cases and ordinary perceptual cases, and I think no pure reliabilist story explains this difference. Moreover, Greco invokes reliability of character to address clairvoyance cases, opening his explanation up to situationist objections and simpler worries in the cases that motivated Harman, Hurka, and Thomsonto deny that virtuous action requires virtuous character.

Still, a version of this objection is decisive against Zagzebski for three reasons. First, Zagzebski's account of the motivational requirement is too strong. Greco (2000) rightly insists that even if it is part of the mechanics of adult knowledge acquisition, it isn't part of the constitutive story. Second, the second clause of Zagzebski's account of knowledge still employs a counterfactual, and it is explanatorily superfluous. Third, as Greco (2000) noted, no particular forms of Zagzebskian motivation (e.g. openmindedness) play a constitutive role even when present. There is hence a

ro But it does invoke to a similar counterfactual fact via the second clause of Zagzebski's analysis of an act of intellectual virtue, which invites a similar objection. 
dilemma for Zagzebski. On the one hand, Zagzebski invites extensional objections: there can be knowledge without acts of intellectual virtue. To avoid these objections, Zagzebski could emphasize the indirectness of her appeal to virtue. But then virtue becomes explanatorily superfluous. ${ }^{\text {I }}$

I take this dilemma to be the most important objection to Zagzebski, and see most other objections as variations on it. For example, Baehr (20II) and Dougherty (20II) invoke cases like Alston's to suggest that Zagzebski fails to explain 'low-grade' knowledge, and Baehr (20 I I: 4O-4I) adds that Zagzebski's mention of virtue loses its explanatory significance if sidelined in some counterfactual clause. The situationist objection is also a variation: since we don't have the relevant character traits, accounts that require them will be extensionally inadequate, and accounts that invoke them counterfactually make them explanatorily superfluous.

Some of Sosa's (20 I 5 ) objections are also variations. Sosa (20 I 5: 48-49) memorably remarks that Zagzebski's motivational requirements aren't met by ' $[\mathrm{h}]$ edge fund managers, waste disposal engineers, and their receptionists, [who] can all attain much knowledge in the course of an ordinary workday despite the fact that they seek the truths relevant to their work only for their instrumental value,' adding that ' $[t]$ hat is why they want them, not because they love truth.' But it is worth separately noting two further objections in the surrounding text:

Independently of all that, it remains that there is a distinctive dimension of epistemic assessment isolated from all such broadly ethical (or prudential) concerns. Moreover, within this epistemic dimension, love of truth plays a negligible role at most, if any at all ...

An assassin may even have no desire whatever for the truth on the location of his victim except only for the fact that it will make his crime possible ... His search for truth, since agential, is subject to the full range of responsibilist assessment nonetheless. And his knowing the location of the victim in believing as he does ... is still epistemically better than his merely believing correctly. (20 I 5: 48-49)

One implicit objection here is to Zagzebski's blurring of moral and epistemic virtue: it is unclear why beliefs with the highest epistemic qualifications must have moral merit or be believed by someone with moral merit. A second implicit objection is to Zagzebski's specific motivational requirement. Sosa allows that his assassin might exhibit responsibilist intellectual virtues. What he denies is that love of truth is an operative virtue, or a desire for truth in general.

II Baehr (20II: 40-4I) also makes this second point. 
These objections are, I believe, compelling against Zagzebski. Versions of the $\mathrm{Y}_{2} \mathrm{~K}$ dilemma's first horn and the situationist objection undermine the appeal to character traits. Sosa's points are compelling against Zagzebski's motivational requirement and her claim that epistemic virtues are moral virtues. The $\mathrm{Y}_{2} \mathrm{~K}$ dilemma's second horn is decisive against Zagzebski's indirect appeal to virtue.

But as I've emphasized, these features of Zagzebski's view are peripheral. It remains to be seen whether similar objections confront versions of AR that drop them. I think not, and I will now turn to develop a version of AR that avoids these objections and has independent attractions.

\section{I0.4 Responsibilism within Reason}

My version of AR is a two-tiered view. The first tier offers a metaphysical analysis of epistemically normative properties in terms of responsibilist virtues I call virtues of respect for truth. Because my view is a version of $A R$, it denies that these virtues admit of analysis in non-responsibilist normative terms. This view is, however, compatible with the naturalist thought that these virtues are in turn grounded in non-normative properties. The first tier's analysis is only intended as a view about the internal structure of the epistemically normative domain, leaving open how it is grounded in the non-normative.

The question of what it takes to manifest the virtues of respect for truth can be answered in several ways. Besides answering it with an analysis of these virtues in non-virtue-theoretic terms, one could answer it by offering a piece of first-order normative theorizing about virtue-making characteristics (by analogy with first-order theories of right action that seek to determine what makes acts right). This observation brings us to the second tier, which is a theory of this kind. Notably, this theory appeals to notions reminiscent of reliabilist VE - in particular, to certain reliable (local) dispositions, and to a distinction among ways of manifesting these dispositions that mirrors Sosa's adroitness/aptness distinction. But in contrast to Sosa, these are proximally dispositions to reliably conform to reasons, and only distally to hit the mark of truth.

I call the overall view 'Kantian responsibilism' (KR). I use this name primarily because it invokes a notion reminiscent of Kantian ethics - viz. respect - but here I understand this as a responsibilist virtue. ${ }^{\mathrm{I} 2}$

I2 I take this view to be consistent with the more systematic Kantian view I defend in Sylvan 2020, because I take the views to operate at different levels. The epistemic Kantianism in Sylvan 2020 is a foundational first-order theory. Kantian responsibilism is a complementary theory working at two 


\section{I0.4.I The First Part of KR: An Analysis of Epistemic Normativity}

According to KR, the most fundamental properties in the epistemically normative domain are virtues of respect for truth. Two are especially crucial. On the one hand, manifesting full respect for truth requires forming doxastic attitudes that conform to epistemic reasons (of some sort) as a manifestation of a disposition to so conform, where epistemic reasons for (dis)belief are understood as indicators of truth and falsity. I'll call this sort of respect heedfulness of the standard of truth (i.e. the standard that it is correct to believe $p$ only if $p$ is true). I don't assume that heedful belief is factive: even if you form a false belief, you might be sufficiently heedful of the standard of truth if your evidence strongly supports it. I also don't assume that heedful belief is transparent: you can be heedful of reasons without realizing that this is what you are doing, and indeed while believing that you're failing to do so.

Partly for that reason, manifesting full respect for truth also requires forming attitudes that cohere with one's beliefs about what the reasons support. I will call this kind of respect conscientiousness relative to the standard of truth. If you follow your convictions about what is required for heeding the standard of truth, you are at least conscientious with respect to that standard.

While full respect for truth requires heedfulness and conscientiousness, there may be cases in which it is impossible to manifest both. Whether there are depends on whether we can have justified false beliefs about what it takes to respect truth. If so, being heedful might require being unconscientious in some cases. These would be epistemic analogues of Arpaly's (2003) Huck Finn case. Just as the intuition is that Huck should heed the real moral reasons and not his false beliefs, so the intuition here assuming the case is possible is that one should be heedful at the cost of being unconscientious. (As it happens, I doubt whether it is possible to have justified false beliefs about what it takes to respect truth, but it is not crucial to resolve this issue here.)

So far, I've been imprecise about the ontology of respect for truth. The reason is that evaluations of respect can have different objects, and there is a further question about which is most fundamental. A person who doesn't have the character trait of being heedful or conscientious relative to the

other levels: the level of analysis, and the level of factoral first-order theory. The 'fundamental role' played by virtue in AR is an analytically fundamental role, not a normatively fundamental role. Hence AR is consistent with there being a deeper normative story, such as epistemic Kantianism. 
standard of truth might manifest heedfulness on some occasions or with respect to some subject matters. When we say that this person manifests some respect for truth, we might mean they manifest a local disposition to form attitudes that are respectful of a certain sort of evidence. Or we might simply mean that they on that occasion formed their beliefs in a respectful way.

My preferred way of regimenting talk of respect is to treat respectfulness of attitude-formation as fundamental, and to see doxastic attitudes as respectful of truth to the extent that they manifest dispositions to form attitudes that are respectful of the evidence and one's beliefs about what is probably true relative to it. We respect truth by respecting evidence and our beliefs about what it supports. We in turn respect the evidence not just by forming the attitudes that happen to conform to the evidence, but rather as a manifestation of a (typically local) evidence-sensitive disposition.

We can use respect talk to pick out character traits and global dispositions, but these play no fundamental role in my view. We might also talk about an attitude of respect. But when I talk about manifesting respect, I don't have in mind that one has a corresponding occurrent attitude, beyond what is minimally involved in manifesting a (typically local) reasons-sensitive disposition.

When I turn to the substantive part of KR, I will say more about what it takes to manifest full respect, and in turn more about what is substantively required for various epistemic statuses. But for now, I'll leave open some substantive details, which are part of the periphery (though one I now endorse).

\section{I0.4.I.I KR's Account of Virtue}

We can now state KR's analyses of various epistemic properties, beginning with the most obvious case: epistemic virtue. KR upholds the following general claim:

$\mathrm{KR}-\mathrm{V}$ : All epistemic virtue properties consist in (manifestations of) forms of respect for truth.

We can then distinguish attitude-attaching and person-attaching virtue properties, as well as between some varieties of the latter:

$\mathrm{KR}-\mathrm{V}_{\text {attitudes: }}$ A doxastic attitude's being epistemically virtuous $=_{\text {df-meta- }}$ physical its being respectful of truth.

$\mathrm{KR}-\mathrm{V}_{\text {person-weak: }}$ A person's being epistemically virtuous in the weak sense ${ }_{\text {df-metaphysical }}$ their tending to have attitudes that respect truth. 
$\mathrm{KR}-\mathrm{V}_{\text {person-strong: }} \mathrm{A}$ person's being epistemically virtuous in the strong sense $=$ df-metaphysical their tending to have attitudes that respect truth as a manifestation of character.

These claims are compatible with a wide range of substantive views, since it is an open question what it takes to respect truth. Still, they are highly non-trivial. Indeed, these claims severely restrict the scope of epistemic virtue in a way that is unusual for responsibilism. Responsibilists often sing praises of intellectual courage, open-mindedness, and the like. While one might try to argue that intellectually courageous and open-minded beliefs are necessarily respectful of truth, these claims are hardly obvious. As far as I'm concerned, this result is a good one: while there is something morally virtuous about open-mindedness and virtuous simpliciter about intellectual courage, it is unclear that these properties necessarily contribute to properly epistemic virtue.

While some responsibilists won't share my taste for an austere conception of the properly epistemic, it is a taste that defenders of AR should, I believe, acquire. For it is false that intellectual courage, open-mindedness, and the like are required for justification, rationality, or knowledge.

\section{I0.4.I.2 KR's Accounts of Justification and Rationality}

This remark brings us to KR's account of the epistemic statuses central to traditional epistemology.

We can start with justification. Like many epistemologists, I think there are several properties often lumped under the heading of 'justification.' I reserve the term 'rationality' for a more subjective status, and 'justification' for a more objective but still perspective-dependent status. This distinction aligns with my distinction between the two main forms of respect for truth, recommending:

KR-R: A doxastic attitude's being epistemically rational = df-metaphysical $_{\text {its }}$ being conscientious relative to the standard of truth.

KR-J: A doxastic attitude's being epistemically justified $=$ df-metaphysical its being heedful of the standard of truth.

Of course, we want beliefs to be both heedful and conscientious. Because I seek to preserve an analogy with ethics, I don't want to capture this point by saying that justification or rationality requires both: an act can be right, and justified, even if the agent believes it is wrong (cf. Huck Finn), and an act can be rational without being justified because it is wrong but the agent believes otherwise, in accordance with how things appear to them. I would 
hence prefer to stipulate a term to refer to the union of the two properties, which I'd call full epistemic worth.

Now, these analyses lack substantive implications independently of a first-order theory of heedfulness and conscientiousness. There are different options I don't want to prejudge. My earlier glosses might seem to suggest that KR is neo-evidentialist: I suggested that one is heedful of the standard of truth by being heedful of the evidence. But as we'll see when turning to my full first-order story, $\mathrm{KR}$ is compatible with reliabilist themes and avoids stock problems for evidentialism.

\section{I0.4.I.3 KR's Account of High-Grade Knowledge}

A disclaimer is in order before I describe KR's take on knowledge.

Earlier I emphasized that $\mathrm{KR}$ is only an account of epistemic normativity, and that not all objects of epistemological investigation are clearly normative. Indeed, I consider the study of what Dretske (1969) called 'epistemic seeing' (seeing that p) as well as the study of remembering that $\mathrm{p}$, intuiting that $\mathrm{p}$, and other factive mental states to be core epistemology. I don't consider any of these states to be normative. If knowledge is just a generic factive mental state, I don't consider it normative either, and favor divorcing the theory of knowledge from the theory of epistemic normativity. ${ }^{\mathrm{I}}$

KR doesn't, however, require this claim. Defenders of KR have several options. First, they could follow Sosa in distinguishing animal knowledge and a fancier sort of knowledge, ${ }^{\mathrm{I} 4}$ offering an account only of the latter. They could then insist that the former isn't normative. Second, they could instead deny that the determinate factive mental states are forms of knowledge, and say that purported cases in which children or dogs have knowledge without respect for truth aren't cases of knowledge but just cases involving determinate factive mental states. Finally, they could insist that even rudimentary knowers can manifest respect for truth, by adopting a first-order theory that only requires respectful subjects to respond to reasons as a manifestation of reasons-sensitive dispositions.

${ }^{13}$ For my defense of this picture, see Sylvan 2018. For antecedents, see Foley 2004 and Kornblith 2009.

${ }^{14}$ I use the term 'high-grade' rather than 'reflective' for greater generality, since not all fans of bi-level epistemology must hold that high-grade knowledge requires reflective ascent. Indeed, in and after his 2010 and 2015 works, Sosa distanced himself from the old label, reserving 'reflective knowledge' for mere meta-apt belief and introducing the new ideas of full aptness and judgmental knowledge to capture the fancier achievement. 
Each option is respectable. For this chapter's purposes, I adopt the first but understand high-grade knowledge broadly, so that most human knowledge and some non-human animal knowledge counts. Having issued these disclaimers, I can now state KR's account of high-grade knowledge:

KR-K: $S$ 's belief that $\mathrm{p}$ is high-grade knowledge $=_{\mathrm{df} \text {-metaphysical }} S$ 's belief that $\mathrm{p}$ is accurate, heedful of the standard of truth, and its accuracy manifests this heedfulness. ${ }^{\text {I5 }}$

This account partly resembles some reliabilist VEs in invoking manifestation (e.g. Sosa [201 5] and Turri [20 I I]). Gettier cases are cases where the belief is accurate and heedful but not accurate as a manifestation of heedfulness. As a result, the view has similar Gettierological payoffs.

There are, however, big differences with reliabilist VE's story, especially if Sosa is the comparison. Recall how in his classic (2007) discussion, Sosa used the animal/reflective knowledge distinction to address fake barn country, claiming that we have animal knowledge but lack reflective knowledge there; while Sosa since his 20 Io and 2015 works has distanced himself from using the 'reflective' label for the highest epistemic achievement, the approach to fake barn country remains similar. My account of high-grade knowledge is structurally more like his account of animal knowledge, since heedfulness needn't be second order. If so, I cannot make Sosa's move.

My response is that there are other ways to diagnose the intuition. It is open to me to offer Littlejohn (2014)'s type of diagnosis: the accuracy of the belief doesn't manifest its heedfulness. It is easy to offer this diagnosis if manifestations of heedfulness coincide with manifestations of a sort of ability (though I don't think Littlejohn's broader point requires his distinction between senses of 'able').

Another difference noted in passing is that KR's account of high-grade knowledge doesn't emphasize the second order. It would if conscientiousness were required for knowledge, or if heedfulness required conscientiousness. But I think neither is true. The core contrast for KR is evinced by the contrast between the knowledge of blindsighters and the knowledge of normal perceivers: it is a first-order difference concerning whether the subject heeded a sufficient reason. Sosa's older

\footnotetext{
is I am using 'accuracy' here in Sosa's sense, to refer to the property that a belief has when its content is true. I am not using it in the new sense introduced by epistemic utility theorists like Pettigrew 2015 .
} 
'animal'/'reflective' lingo is hence misleading: the core distinction is between knowledge understood as registration of facts and knowledge understood as Reason-produced accuracy.

\section{I0.4.2 The Second Part of KR: A Substantive Account of What Respect Requires}

The first tier of KR doesn't give enough information to derive clear predictions about cases. I'll now provide this information. But it is worth stressing that this feature of the first tier is no bug, given its point. The point was to limn the internal structure of a normative domain. This kind of project is standard in meta-ethics. Compare the fitting-attitudes account of value, according to which being valuable consists in being a fitting object of valuing. It is no objection to this view that it makes no clear predictions about what is valuable, which is not its point. It is also no objection that it appeals to normative notions.

Still, besides wanting a real definition of various epistemically normative properties in fundamental normative terms, one wants a story about what it takes for the definiens to be instantiated. My story reveals the deliberate ambiguity of my title. This story is 'within reason' not only in the sense of being reasonable to accept, but also in linking responsibilist virtues to the abilities that constitute the faculty of theoretical reason.

Some preliminary clarifications are in order about the nature of the story. This account will appeal to the notion of a reason, which in metaethics is standardly taken to be the paradigm of normativity. But this feature doesn't contravene the normative fundamentality of responsibilist virtue, for two reasons. First, because the account is first order rather than meta-normative, it doesn't follow that the account ultimately takes reasons rather than virtues to be analytically prior. Second, reasons can be analyzed in terms of responsibilist virtues: roughly, reasons are considerations that figure in the virtuous operation of theoretical reason. This account combines the Kantian aspiration of explaining reasons in terms of Reason familiar from Korsgaard (2008, 2009, 20II), with virtue-ethical doubts about whether reason-relations can be captured by simple principles familiar from McDowell (I979) and Dancy (2004). While I am not as skeptical in the epistemic case as Dancy and McDowell are in the ethical case that simple principles can be found, I don't see a helpful way of stating them without implicitly adverting to responsibilist virtue.

A second clarification is in order. One might worry that my appeal to reason conflicts with the spirit of $\mathrm{VE}$, which was meant to supplant 
'intellectualist' models of epistemic normativity. ${ }^{\mathrm{I}}$ 'The response to this concern is that it rests on implicit overintellectualization of the workings of reason. As Dancy (2003: 277-278) notes in the non-epistemic case, reasons-responsiveness needn't involve inference (when inference is understood as involving rule-following):

$[\mathrm{m}]$ oral thinking ... can perfectly well be thought of as reasoning just in the sense that it is deliberation, i.e., the discerning of interrelations of reasons[, which] involves two basic stages. First, one recognizes what reasons are thrown up in the situation one is in; this is not inference ... Secondly, one works out what those reasons require of one. This sort of working out need not be thought of as inference either.

Responding to epistemic reasons can work in this way. After pondering the evidence, one might treat it as favoring the best-supported hypothesis via a reasons-sensitive competence. This process needn't involve inference, at least when understood in the natural sense that involves rule-following. ${ }^{17}$ Still, it is reasoning - a working out of what the evidence recommends via Reason.

I0.4.2.I Responsibilist Virtues, Rational Capacities, and Reasons

The idea of linking responsibility and Reason is standard in the philosophy of action. Over there, there has been a shift away from the 'true self model of responsibility - a model that perhaps implicitly guided earlier responsibilists to fixate on character - and toward the reasons-responsive models of Wolf (I994), Fischer and Ravizza (I998), and Nelkin (201 I). The core of this conception of responsibility is that responsible creatures are creatures with the capacity to respond to reasons. The exercise of responsibility consists in the 'rational control' of actions and attitudes by rational capacities, which are dispositions to respond to reasons. This model has been extended to the epistemic case by Hieronymi (2008) and McHugh (2014).

Of course, such models are merely intended to capture responsibility in the weak sense associated with accountability, which one can manifest while being blameworthy. But the capacities invoked by these theorists can operate more or less well. The well functioning of these capacities will consist in responsiveness to good reasons. Given this point, we can exploit certain structural distinctions familiar from performance epistemology to

\footnotetext{
${ }^{16}$ Consider Code 1984: 39, who takes inspiration from Sosa 1980 in rejecting what both call the 'Intellectualist Model of Justification.'

${ }^{17}$ For further discussion of inference and its relation to reasons-responsiveness, see Sylvan 20 I6b.
} 
illuminate the distinctions among exercises of rational capacities that suffice for various epistemic statuses.

My substantive account of virtue invokes reasons-sensitive dispositions. These dispositions proximally function to respond to reasons understood as they are standardly understood in ethics - viz. as facts that count in favor of acts and attitudes, where these facts are not necessarily ones to which we have access. Of course, for the view to remain true to the spirit of responsibilism, the favoring relation and the relation of correctly responding to reasons ('proper basing') might need analyzing in responsibilist terms. ${ }^{18}$ But even without such an analysis, appealing to reasons at this tier doesn't involve any commitment to normative fundamentality: this tier isn't an account of the constitution of epistemic normativity but rather a first-order account.

Now, one might separately worry about the appeal to reasons understood as facts, insisting that only reasons we possess can epistemically justify. I agree with the latter claim, but don't think it threatens the helpfulness of such reasons for understanding epistemic normativity. Possession needn't be understood normatively. If we understand possessing a reason as accessing the fact that provides it, we can then understand access in terms of factive mental states like seeing that $p$, remembering that $p$, intuiting that $\mathrm{p}$, and so on. ${ }^{19}$

One might also insist that when it comes to rationality, the reasons to which one responds in exemplifying this virtue need only be apparent facts. But again, we needn't understand the relevant notion of appearance normatively: an apparent fact is just one that non-doxastically seems to obtain.

A final preliminary note: I assume that the paradigm examples of epistemic reasons are pieces of evidence, understood as truth-indicating facts or apparent facts. I don't assume that only these can provide epistemic reasons. Epistemic reasons for agnosticism will include considerations about the evidence (e.g. whether it is sufficient). Perhaps these are just higher-order evidence. But I'll remain neutral, assuming only evidence provides the paradigm example of an epistemic reason for (dis)belief, and

${ }^{18}$ One could also take this relation to be non-normative: perhaps the evidence-for relation isn't normatively constituted, and the capacities constitutive of theoretical reason are capacities to respond to evidence.

I9 Note that if accessing a fact is understood as a determinable factive mental episode that takes as determinates factive mental episodes like seeing that $\mathrm{p}$ and remembering that $\mathrm{p}$, there is no need to impose any normative qualification on such access (e.g. to qualify it as proper access). I take this way of understanding access to be more intuitive than an understanding that would count mere believing as a form of access. It is counterintuitive to claim that mere belief that $\mathrm{p}$ gives one access to the fact that $\mathrm{p}$ (though pre-Williamsonian epistemologists often talked otherwise). 
that the yardstick of sufficiency tracks whether heeding the reasons would be respectful of truth.

\section{I0.4.2.2 Conditions for Respectful Belief-Formation}

We now have the necessary ingredients for a substantive account of our responsibilist virtues and the epistemic statuses they ground. ${ }^{20}$

We can begin with the thought that the responsibilist virtues coincide substantively with certain rational capacities. Epistemic rational capacities in turn are dispositions to form doxastic attitudes in certain conditions, and to take certain kinds of considerations into account in doxastic deliberation. Here there are two sets of crucial distinctions: distinctions concerning the extent to which (i) these dispositions qualify as rational capacities, and (ii) these dispositions qualify as manifestations of rational capacities. Corresponding to these distinctions will be substantive conditions for various forms of respect for truth, and for respectful attitudeformation.

A disposition to form doxastic attitudes of type $\mathrm{D}$ in conditions of type $\mathrm{C}$ qualifies as a minimal rational capacity if conditions of type $\mathrm{C}$ constitute sufficient apparent epistemic reasons for attitudes of type D. A disposition to form doxastic attitudes of type $\mathrm{D}$ in conditions of type $\mathrm{C}$ qualifies as a full rational capacity if conditions of type $C$ constitute sufficient possessed epistemic reasons for doxastic attitudes of type $\mathrm{D}$, where these reasons aren't merely apparent.

When the 'apparent' is understood as 'apparent relative to one's doxastic attitudes,' having a disposition of the first sort coincides as a first-order matter with local conscientiousness relative to the standard of truth. When the 'apparent' is understood relative to the non-doxastic appearances, having a disposition of the first sort coincides as a first-order matter with weak local respectfulness of the standard of truth. Having a disposition of the second sort coincides as a substantive normative matter strong local respectfulness of the standard of truth.

These dispositions can in turn be manifested in different ways. Suppose one seeks to predict the behavior of some object, relying on an inductive disposition to form predictions of type $\mathrm{T}$ given evidence of

20 This substantive account remains high level, since there are further questions about when (apparent) facts provide (apparent) evidence. But substantive normative theorizing has levels of its own: as Kagan 1997 stresses, normative ethics operates at two levels of generality, with factoral normative theorizing seeking just to articulate all factors relevant to the exemplification of normative properties, and foundational normative theorizing seeking an account of which factors are most fundamental. See Sylvan 2020 for the foundational story. 
type E. This disposition is a minimal rational capacity. A belief might manifest this capacity despite the evidence being misleading or merely apparent. But it might manifest this capacity when the evidence is not misleading. It might be

- correct as a manifestation of a full rational capacity,

- manifest a full rational capacity but be correct just by luck,

- incorrect but manifest a full rational capacity,

- incorrect but manifest a minimal rational capacity.

Each case corresponds to a substantive condition for some form of respect:

- Fully respectful belief: A belief is fully respectful iff correct as a manifestation of its responsiveness to possessed epistemic reasons (where this is mediated by a full rational capacity).

- Strongly heedful belief: A belief is strongly heedful iff it conforms to possessed epistemic reasons as a manifestation of a full rational capacity.

- Weakly heedful belief: A belief is weakly heedful iff it conforms to apparent epistemic reasons in the non-doxastic sense of 'apparent' as a manifestation of a minimal rational capacity.

- Conscientious belief: A belief is conscientious iff it conforms to apparent epistemic reasons in the doxastic sense of 'apparent' as a manifestation of a minimal rational capacity.

There are intermediate cases between the first and second statuses. These are Gettier cases: the belief will be correct and reasons-responsive, but not correct as a manifestation of reasons-responsiveness.

10.4.2.3 Conditions for Justification, Rationality, and High-Grade Knowledge We can now turn to substantive conditions for the various epistemic statuses and see the case for a further distinction among sorts of rationality. From KR-R and the substantive conditions for conscientiousness, we can derive the following conditions for rationality:

KR-RS: A doxastic attitude is rational iff it conforms to apparent epistemic reasons in a doxastic sense of 'apparent' as a manifestation of a minimal rational capacity.

This thesis illuminates rationality in the structural sense standard in ethics (e.g. in Scanlon [1998], Kolodny [2005], and Broome [2013]), which Worsnip (2018) encourages epistemologists to take into account, and which has an antecedent in Foley's (1987) notion of rationality. This 
notion of rationality doesn't correspond neatly to the sort that interests internalists in epistemology. But note that we can divide KR-R into two claims, with the distinction between conscientious and weakly heedful belief providing the foundation:

KR-R-: A doxastic attitude's being structurally rational $=$ df-metaphysical its being conscientious relative to the standard of truth.

KR-R+: A doxastic attitude's being substantively rational $=_{\text {df-metaphysical }}$ its being weakly heedful relative to the standard of truth.

We can then also divide KR-RS into two claims:

KR-RS-: A doxastic attitude is structurally rational iff it conforms to apparent epistemic reasons in a doxastic sense of 'apparent' as a manifestation of a minimal rational capacity.

KR-RS+: A doxastic attitude is substantively rational iff it conforms to apparent epistemic reasons in the non-doxastic sense of 'apparent' as a manifestation of a minimal rational capacity.

Both sorts of rationality then turn out distinct from justification if the latter is understood in terms of strong heedfulness, via the following precisification of KR-J:

KR-J+: A doxastic attitude's being justified $=_{\text {df-metaphysical }}$ its being strongly heedful with respect to the standard of truth.

Given the substantive conditions for strong heedfulness, we can then derive:

KR-JS+: A doxastic attitude is justified iff it conforms to possessed epistemic reasons as a manifestation of a full rational capacity.

Finally, we get substantive conditions for high-grade knowledge by understanding high-grade knowledge as fully respectful belief and invoking the substantive conditions for the latter:

KR-KS: A belief is high-grade knowledge iff it is correct as a manifestation of its responsiveness to possessed epistemic reasons (where this manifestation is mediated by a full rational capacity).

The result is a complete first-order normative epistemology for the most central epistemic statuses.

Extensionally, this view will fall somewhere between evidentialism and Sosa's (2015) performance epistemology for judgment. It is unlike evidentialism in three respects. First, it fundamentally provides substantive conditions for doxastic justification. Second, unlike Conee and Feldman's 
(2004) evidentialism, the notion of a reason to which this view appeals is non-mentalist. Of course, only possessed reasons do much epistemic work. But possession is a relation that holds in virtue of factive mental states, not the non-factive ones of Conee and Feldman's mentalism. Although reasons that appear to exist relative to non-factive mental states play some role, cognition doesn't aspire merely to respond to these apparent reasons. A third difference is that $\mathrm{KR}$ invokes dispositions to conform to reasons, inducing a threefold pattern reminiscent of Sosa's AAA pattern. A belief can

- merely conform to some reasons (by being favored by them);

- manifest a reasons-sensitive disposition;

- conform as a manifestation of a reasons-sensitive disposition.

The view is, however, not extensionally equivalent to Sosa's, since Sosa doesn't require reasons-responsiveness even at the judgmental level. I've argued elsewhere that this feature of Sosa's view is problematic, so I take the difference to represent an advantage for $\mathrm{KR}^{2 \mathrm{I}}$

\section{I0.4.3 A Consistent Reduction Plan}

To remain true to responsibilism, we need an analysis of epistemic reasons either in responsibilist terms or in terms that render reasons nonnormative. My preference is for a version of the first option that makes KR Kantian in a further way, but I think there are respectable versions of the second.

Before discussing either option, I'll stress again that it is compatible with these metaphysical stories that we have independent conceptual grasp on epistemic reasons and the conditions under which they make beliefformation respectful. If we have this grasp, we don't need the reductions below to derive clear predictions from my two-tiered account. And we do, I believe, have sufficient pre-theoretical grasp of the concept of a reason for the account to be predictive. The point of this section, then, is merely to show that appealing to reasons in a first-order theory doesn't contravene the metaphysical claim that responsibilist virtues come first.

\section{I0.4.3.I A Consistently Kantian Reduction Plan}

Following Way (2015), Gregory (2016), and Silverstein (2016), defenders of the first reduction plan will first invoke a high-level analysis of reasons as

2I See Sylvan forthcoming. 
inputs to good reasoning, where 'reasoning' is understood broadly to include non-inferential transitions like the transition from seeming to see that $p$ to believing that $p$. Good theoretical reasoning is then analyzed as reasoning that is respectful of truth, where there is no commitment to such reasoning being economically codifiable without invoking responsibilist normativity (otherwise the view would be fundamentally just Kantian, not virtue-theoretic). We needn't deny that good reasoning follows patterns, however: it is just that nothing holds them together apart from their contributions to respect for truth.

There is a further Kantian step we can take without sacrificing this virtue-theoretic theme. We can give a constitutivist reduction of theoretical normativity, viewing good patterns of reasoning as patterns constitutive in the sense that thought must often enough conform to them to count as reasoning at all. This step also shows how we might ground epistemic normativity in the non-normative: the study of epistemic normativity is the study of the statuses associated with patterns of thought constitutive of theoretical reasoning, full sensitivity to which constitutes respect for truth.

\section{I0.4.3.2 Non-Normativism about (Epistemic) Reasons?}

A different option is to deny that invoking reasons is invoking some nonresponsibilist normative property, by denying that reasons are essentially normative. This option flouts the recent meta-ethical chant that has it that reasons are the paradigmatic normative items. To those entranced by this chant, this option will seem bewildering. But it has been pursued by Broome (2004) and Finlay (2014), who take the fundamental notion of a reason to be explanatory, and take normative reasons to be a special case of reasons so understood. On this view, normative reasons are normative only in virtue of being explanations of normative facts.

Now, Broome and Finlay appeal to non-virtue-theoretic normative notions: for Broome, reasons to $\phi$ are explanations of why one ought to $\phi$, while for Finlay, reasons are explanations of things are good in some way. But one could imagine a virtue-theoretic variant on which reasons provide explanations of why certain attitudes would be virtuous in a responsibilist sense.

A different option would treat epistemic reasons specifically as nonnormative. The most obvious version of this view would combine the view that all epistemic reasons are evidence with the view that the evidence-for relation is non-normative, consisting perhaps in some truthindication or probabilification relation, with probability understood nonnormatively. 


\section{I0.5 Answers to the Standard Objections}

Whichever form it takes, the view I've outlined dispatches with the standard objections to AR.

The first horn of the $\mathrm{Y}_{2} \mathrm{~K}$ dilemma is easily addressed. To be sure, KR imposes requirements that one might call 'motivational. ${ }^{\prime 22}$ But as a substantive matter, these requirements will be met by subjects who attain the relevant epistemic statuses. For given our first-order story, it will be fine to ascribe such respect to justified believers and high-grade knowers. While it is not uncontroversial that rationality, justification, and high-grade knowledge require responding to reasons, these claims are defensible and cannot be rejected out of hand. Indeed, these claims have been defended by some reliabilist virtue epistemologists when reasons are understood as I've understood them. ${ }^{23}$

The further requirement that this responsiveness manifest a form of reasons-sensitivity enables $\mathrm{KR}$ to secure reliabilist VE's good predictions about cases of accidental conformity to reasons. In Greco's (2000: I83) example of the poor math student who accidentally lands on a correct algorithm for solving a problem, such sensitivity is not manifest. It would be a mistake to insist that reliability of character is what's really needed. Poor math students can manifest understanding of some algorithms, and when they solve problems as a manifestation of that understanding, they attain justified belief and perhaps high-grade knowledge. Character-based views undergenerate epistemic status in such cases.

The second horn of the $\mathrm{Y}_{2} \mathrm{~K}$ dilemma is straightforwardly addressed if it takes Kornblith's form. Kornblith was worried about the explanatory helpfulness of Zagzebski's merely counterfactual appeal to virtue properties. Our view doesn't make a counterfactual appeal: it requires that the justified believer actually manifest respect. So, it cannot face Kornblith's worry.

Greco's version of the worry is more interesting. He insists that it is unclear what explanatory role Zagzebski-type virtues as such play. Here he invokes a sub-dilemma. He observes that the success component of Zagzebski-style virtues can be understood either to yield truth-reliability

22 Matt Stitcher emphasized in p.c. that it is unclear that respect for truth is a kind of motivation rather than a kind of deliberative constraint. I agree that respect isn't any sort of desire. As an anti-Humean about motivation, I don't think it follows that respect isn't a kind of motivation. Perhaps more revealing is the point that the person who manifests respect for truth needn't have any thoughts about the value of truth among their reasons.

23 See Sylvan and Sosa 2017, where Sosa agrees that rationality and justification entail reasonsresponsiveness. 
or to not do so. If the latter holds, Greco thinks the account makes bad predictions: math students who follow unreliable algorithms accidentally but are generally responsible in Zagzebski's sense won't thereby have justified beliefs. If the former holds, Greco (2000: I 84) thinks 'it is the agent-reliability that is doing the work, and nothing about Zagzebski-type virtues as such.'

But this last claim doesn't extend to KR for two reasons. The first is a general reason that also helps Zagzebski. The fact that reliability is necessary for manifesting responsibilist virtues obviously doesn't imply that it is sufficient. Clairvoyance cases suggest that a responsibilist virtue property is also necessary, as Greco (2010: 42) agrees. Perhaps it isn't necessary for animal knowledge, and perhaps clairvoyants have such knowledge. But one can use this point to argue that animal knowledge is not normative, and hence not among KR's analysanda. ${ }^{24}$

Now, one might instead complain that it is ad hoc for Zagzebski to stipulate that responsibilist virtues are truth-reliable, and that our intuitive notions of, e.g., open-mindedness and intellectual courage don't entail truth-reliability. One might hence worry that there isn't a principled responsibilist rationale for this requirement. But KR avoids this objection. Sensitivity to reasons understood as facts is constitutive of what I earlier called strong heedfulness, which does entail at least indexical truthreliability (and one might take the new evil demon problem to suggest this is all we can demand).

There is a third way to make Greco's point, but it requires a normative analogue of the exclusion principle that threatens any appeal to virtue. One might argue that the properties in my substantive account of respect do the explanatory work, and that the supervening respect isn't doing any work. But this objection overgeneralizes. The reasoning is only compelling given the more general principle that the properties subvening normative statuses do the real work. This principle suggests that the non-normative properties that subvene any virtue properties do the work, not the virtue properties as such. Such, at any rate, follows barring a naturalist identity theory. Yet such a theory is open to the responsibilist too, particularly if they adopt the Kantian strategy of Section I0.4.3.I.

To avoid overgeneralization, the objector must provide a more minimal supervenience base that can do the explanatory work without subvening respect for truth. But we need sensitivity to reasons to get the right predictions about clairvoyance cases, and it subvenes respect for truth.

${ }^{24}$ See Sylvan 2018 for such an argument. 
Perhaps there is some other story, but one hasn't been given; again, Greco himself agrees that clairvoyance cases necessitate a responsibilist requirement for justification.

So much for the $\mathrm{Y}_{2} \mathrm{~K}$ dilemma. KR also addresses Sosa's objections. Now, Sosa (201 5: 49) does mention respect for truth in passing. He dismisses the idea, claiming that his hedge fund managers and waste disposal engineers needn't have such respect to attain justification or knowledge. But his dismissiveness rests on a failure to distinguish the relevant notion of respect from the irrelevant notion Darwall (I977) calls 'appraisal respect.'

Appraisal respect amounts to esteem, and requires having a 'high opinion' of the object of respect. By contrast, recognition respect in Darwall's (I 977) sense just requires giving the object of respect 'appropriate weight in deliberation.' Yet if hedge fund managers and waste disposal engineers exhibit sensitivity to evidence, they do then exhibit recognition respect for truth, by giving appropriate weight in their doxastic deliberation to facts about what's probably true given their evidence. Hence, Sosa's alleged examples of justification without respect for truth are only examples of justification without appraisal respect for truth, not without recognition respect for truth. If we stipulate that the subjects lack recognition respect for truth - i.e. that they don't appropriately take truth-related reasons into account - my intuitions change. The cases then don't seem to be cases of justified belief.

Recognition respect for truth doesn't require love of truth or the norms of truth: one might wish that one could avoid playing by these rules, despite playing by them on pain of epistemic irrationality. All it requires, in Darwall's idiom, is appropriately taking truth-related considerations into account. That is another way of saying that it only requires being heedful of the epistemic reasons. That is intuitively required for justification.

KR also avoids Sosa's unwanted blurring of the moral and the epistemic. Admittedly, talk of respect sounds more natural in the moral case. But the general notion of recognition respect isn't distinctively moral, nor is the moral case the only case in which recognition respect matters. ${ }^{25}$ One can act with or without recognition respect for any rule, and exhibiting recognition disrespect is sufficient for blameworthiness relative to the rule as a general matter. The epistemic case is just a special case: failures of respect for truth make epistemic blame fitting, manifestations of weak respect make epistemic excuse fitting, and strong respect entails justification. KR only

25 Darwall (2006) now uses recognition respect in an essentially second-personal way, but the original notion was more general, and could take mere objects and norms as objects. 
commits us to a structural analogy between epistemology and morality, and doesn't automatically yield moral encroachment. ${ }^{26}$

I conclude, then, that none of the strongest philosophical objections to earlier versions of AR extend to KR. ${ }^{27}$

\section{I0.6 Concluding Remarks}

I think I've done enough to show that the stock objections to AR rest on mistaking its periphery for its core. Of course, KR's mere avoidance of objections doesn't give us sufficient reason to accept it, let alone prefer it to reliabilist VE or non-virtue-theoretic views. But while a wholesale defense of KR would take another paper, we can conclude with some reasons to prefer it.

The main point to make is that KR shares the attractions but lacks the vices of its competitors. Let's take the non-virtue-theoretic competitors first. By resting on a substantive appeal to reasons-sensitivity, KR absorbs the attractions of evidentialist approaches. But it avoids their flaws for the same reason. Perhaps most importantly, as I've argued elsewhere, ${ }^{28}$ the requirement that justified beliefs conform to reasons as a manifestation of sensitivity to reason-relations addresses the improper basing objections reliabilists have pressed. The same feature enables KR to circumvent the speckled hen problem: while the belief that the hen has 48 speckles might conform to the evidence, it couldn't do as a manifestation of a disposition to conform.

Similar claims go for the comparison with reliabilism. Sensitivity to objective reason-relations entails reliability, and so KR secures the payoffs yielded by making reliability necessary for justification. But because KR does not take reliability to be sufficient for justification, it promises to avoid the clairvoyance problem, especially if reasons-sensitivity is understood as sensitivity to facts to which one has conscious access (as I did). Moreover, by drawing a distinction between rationality and justification that rests on a principled distinction among reasons drawn outside epistemology, the account also avoids the new evil demon problem. That problem collapses

\footnotetext{
${ }^{26} \mathrm{KR}$ is not incompatible with moral encroachment. One could hold a substantive view of respect for truth that requires testimonial justice, where this is morally encroached. Indeed, Fricker's (2007) responsibilist epistemology of testimony resembles my general epistemology, similarly resting on a framework of reasons-sensitive dispositions.

27 By avoiding the ideology of character, KR also avoids the empirical objections of situationists, as I argue in Sylvan 2017.

${ }^{28}$ See Sylvan 2016a and Lord and Sylvan forthcoming.
} 
into the problem of giving a rationale for denying justification but according an inferior status to demon-worlders, which KR offers.

What about KR's virtue-theoretic competitors? Some reasons to prefer $\mathrm{KR}$ to these repeat reasons for preferring $\mathrm{KR}$ to pure reliabilism. Unadulterated versions of virtue reliabilism don't explain the epistemic status lacking in clairvoyants. ${ }^{29} \mathrm{KR}$ is also preferable to hybrid versions of VE. These can seem ad hoc, giving no unified reason for thinking that both reliabilist and responsibilist properties are constitutive of virtue. KR, by contrast, derives reliabilist and evidentialist themes from a unified core that invokes responsiveness to reasons understood as they are in ethics, as facts that objectively favor acts and attitudes. Furthermore, KR does so without the excesses of previous responsibilisms.

I conclude, then, that we have strong reason to take KR seriously as a competitor to virtue reliabilism and non-virtue-theoretic approaches.

\section{REFERENCES}

Alfano, M. 20I2. 'Expanding the Situationist Challenge to Responsibilist Virtue Epistemology,' Philosophical Quarterly 62: 223-249.

Alston, W. 1989. Epistemic Justification. Ithaca, NY: Cornell University Press. 2000. 'Virtue and Knowledge.' Philosophy and Phenomenological Research 60: I $85-189$.

Arpaly, N. 2003. Unprincipled Virtue. Oxford: Oxford University Press.

Baehr, J. 20 I I. The Inquiring Mind. Oxford: Oxford University Press.

Broome, J. 2004. 'Reasons,' in Wallace, R. Jay et al. (eds), Reason and Value: Themes from the Moral Philosophy of Joseph Raz. Oxford: Oxford University Press. 2013. Rationality through Reasoning. Oxford: Blackwell.

Code, L. I984. 'Toward a 'Responsibilist' Epistemology,' Philosophy and Phenomenological Research 45: 29-50.

Conee, E. and Feldman, R. 2004. Evidentialism: Essays in Epistemology. Oxford: Oxford University Press.

Dancy, J. 2003. 'Critical Study of Paul Grice, Aspects of Reason,' Philosophical Quarterly 53: 274-279. 2004. Ethics without Principles. Oxford: Oxford University Press.

Darwall, S. 1977. 'Two Kinds of Respect,' Ethics 88: 36-49. 2006. The Second-Person Standpoint. Cambridge, MA: Harvard University Press.

Dougherty, T. 20 I I. 'Knowledge Happens: Why Zagzebski Has Not Solved the Meno Problem,' Southern Journal of Philosophy 49: 73-88.

Dretske, F. 1969. Seeing and Knowing. Chicago, IL: University of Chicago Press. I98 I. Knowledge and the Flow of Information. Stanford, CA: CSLI Publications.

29 See Sylvan forthcoming, for a full defense of this claim. 
Finlay, S. 20I4. A Confusion of Tongues. Oxford: Oxford University Press.

Fischer, J. M. and Ravizza, M. I998. Responsibility and Control. Cambridge, UK: Cambridge University Press.

Foley, R. 1987. The Theory of Epistemic Rationality. Cambridge, MA: Harvard University Press.

2004. 'A Trial Separation between the Theory of Knowledge and the Theory of Justified Belief,' in Greco, J. (ed.) Ernest Sosa and His Critics. Oxford: Blackwell.

Fricker, M. 2007. Epistemic Injustice. Oxford: Oxford University Press.

Goldman, A. I. 1967. 'A Causal Theory of Knowing,' Journal of Philosophy 64: 357-372.

1979. 'What Is Justified Belief?' in Pappas, G. (ed.), Justification and Knowledge. Dordrecht: D. Reidel.

Greco, J. 2000. 'Two Kinds of Intellectual Virtue,' Philosophy and Phenomenological Research 60(I): 180-185. 2010. Achieving Knowledge. Cambridge, UK: Cambridge University Press.

Gregory, A. 2016. 'Reasons as Good Bases,' Philosophical Studies 173: 2291-2310.

Harman, G. 200I. 'Virtue Ethics without Character Traits,' in Byrne, A., Stalnaker, R., and Wedgwood, R. (eds), Fact and Value. Cambridge, MA: The MIT Press.

Hieronymi, P. 2008. 'Responsibility for Believing,' Synthese I6I: 357-373.

Hurka, T. 2006. 'Virtuous Acts, Virtuous Dispositions,' Analysis 66: 69-76.

Kagan, S. 1997. Normative Ethics. Boulder, CO: Westview Press.

Kolodny, N. 2005. 'Why Be Rational?' Mind I I 4: 509-563.

Kornblith, H. 2000. 'Linda Zagzebski's Virtues of the Mind,' Philosophy and Phenomenological Research 60: 197-20I.

2009. 'Knowledge Needs No Justification,' in Smith, Q. (ed.), Epistemology: New Essays. Oxford: Oxford University Press.

Korsgaard, C. 2008. The Constitution of Agency. Oxford: Oxford University Press. 2009. Self-Constitution. Oxford: Oxford University Press.

20 I I. 'The Activity of Reason,' in Wallace, R. J., Kumar, R., and Freeman, S. (eds), Reasons and Recognition. Oxford: Oxford University Press.

Kvanvig, J. 1992. The Intellectual Virtues and the Life of the Mind. Lanham, MD: Rowman \& Littlefield.

Littlejohn, C. 2014. 'Fake Barns and False Dilemmas,' Episteme i r: 369-389.

Lord, E. and Sylvan, K. Forthcoming. 'Believing for Normative Reasons: Prime, Not Composite,' in Bondy, P. and Carter, J. A. (eds), Well-Founded Belief: New Essays on the Basing Relation. London: Routledge.

McDowell, J. I979. 'Virtue and Reason.' The Monist 62: 33 I-350.

McHugh, C. 20I4. 'Exercising Doxastic Freedom,' Philosophy and Phenomenological Research 88: I-37.

Nelkin, D. 20I I. Making Sense of Freedom and Responsibility. Oxford: Oxford University Press.

Olin, L. and Doris, J. 201 2. 'Vicious Minds,' Philosophical Studies I 68: 665-692.

Pettigrew, R. 20 I 5. Accuracy and the Laws of Credence. Oxford: Oxford University Press. 
Parfit, D. 20I I. On What Matters (Vol. I). Oxford: Oxford University Press.

Roberts, R. C. and Wood, J. C. 2007. Intellectual Virtues. Oxford: Oxford University Press.

Scanlon, T. M. I998. What We Owe to Each Other. Cambridge, MA: Harvard University Press.

20 I I. 'The Unity of the Normative,' Philosophical Studies I 54: 443-450. 20 I 4. Being Realistic about Reasons. Oxford: Oxford University Press.

Schroeder, M. 2007. Slaves of the Passions. Oxford: Oxford University Press.

Silverstein, M. 2016. 'Reducing Reasons,' Journal of Ethics and Social Philosophy IO(I): I-22.

Sosa, E. 1980. 'The Raft and the Pyramid,' Midwest Studies in Philosophy 5: 3-26. I 991. Knowledge in Perspective. Cambridge, UK: Cambridge University Press. 2015 . Judgment and Agency. Oxford: Oxford University Press.

Sylvan, K. 20I6a. 'Epistemic Reasons I: Normativity,' Philosophy Compass i I: $364-376$.

20I6b. 'Epistemic Reasons II: Basing.' Philosophy Compass I I (7): 377-389.

2017. 'Responsibilism out of Character,' in Fairweather, A. and Alfano, M. (eds), Epistemic Situationism. Oxford: Oxford University Press.

2018. 'Knowledge as a Non-Normative Relation,' Philosophy and Phenomenological Research 97: 190-222.

2020. 'An Epistemic Nonconsequentialism,' Philosophical Review I 29(I): I-5 I. Forthcoming. 'Can Performance Epistemology Explain Higher Epistemic Value?' Synthese.

Sylvan, K. and Sosa, E. 2018. 'The Place of Reasons in Epistemology,' in Star, D. (ed.), The Oxford Handbook of Reasons and Normativity. Oxford: Oxford University Press.

Thomson, J. J. 1997. 'The Right and the Good,' The Journal of Philosophy 94: $273-98$.

Way, J. 2015. 'Reasons as Premises of Good Reasoning,' Pacific Philosophical Quarterly. Online first. DOI: doi:Io.I I I I/papq.I2I35

Wolf, S. I 994. Freedom within Reason. Oxford: Oxford University Press.

Worsnip, A. 20I8. 'The Conflict of Evidence and Coherence,' Philosophy and Phenomenological Research 96: 3-44.

Zagzebski, L. 1996. Virtues of the Mind. Cambridge, UK: Cambridge University Press.

2003. 'Intellectual Motivation and the Good of Truth' in DePaul, M. and Zagzebski, L. (eds), Intellectual Virtue. Oxford: Oxford University Press.

Zimmerman, M. 2002. 'Taking Luck Seriously,' The Journal of Philosophy 99: $553-576$. 